\title{
Literature Review on the Budget Slack
}

\author{
Shujun Sheng \\ Tianhua College \\ Shanghai normal university \\ Shanghai, 201815, China
}

\begin{abstract}
Budget, one of the significant mechanisms to allocate the organizational resources, affects the cost and performance of the organization through the advanced allocation with resources. However, budget slack, as the unexpected behavior of budgetary management, has undoubted effects on the organization. On the basis of the research and conclusion with the former literature, this paper briefly introduces the definition, affecting factors and economic effects of budget slack, in hope of helping promoting the budget performance of modern management accounting.
\end{abstract}

Keywords—budget slack; agency theory; contingency theory

\section{INTRODUCTION}

Budget means that enterprises plan the allocation of future resources, control and coordinate the internal economic activities. From the perspective of the plan, the budget should reflect the actual conditions, the most appropriate resource demands and arrangement, and it is objective technical process. From the perspective of control, budget passes the strategic intent of the organization, has the economic effect after distributing the profit, and it is affected by the subjective factors of the upper and lower levels. Due to the objectives existing mutual relationships and conflicts, it is rather difficult to assess the result of budget management. Therefore, all scholars do researches with the performance assessment of the budget management from different angles[4], like the influence of behaviors. In addition, most of them make adverse inspection and research on the unexpected behaviors of budget management. The budget slack discussed in this paper belongs to the unexpected behavior of budget management.

It is opposite to the "budget plan reality". Regarding to the specific definition of budget slack, scholars give different definitions. Merchant (1985a) said that it referred to the amount exceeding its budget amount. In fact, this definition is just suitable to the cost budget like administration expense. Lukka (1988) thought the so-called budget slack was opposite to honest budget estimate. Young (1985) came up with the definition from the perspective of assessing the performance. He thought it meant the part that staff underestimates when they have the choice to select the evaluation standards. While Waller (1988) thought that slack meant the extra consuming resources than the needed. On the basis of the above definitions, Dunk and Nouri (1998) defined it as intentionally underestimated income or capacity, and the overestimated cost or resource when some budget task was finished. The definition made rather comprehensive summary with the content of budget slack, and it clarified that it happened in finishing some budget task to make the managers have more accurate definition with budget slack behaviors.

\section{RESEARCH ON THE FACTORS INFLUENCING THE BudGET SLACK}

Lots of experimental proof have showed that the budget slack in the organization is very common (Merchant, 1985; Merchant and Manzoni, 1989)[5]. Schif and Lewin (1970), who firstly put forward the concept of "budget slack", pointed out: "We find that managers have the demand of operating in slack environment. And managers underestimate the profit and overestimate the cost so as to establish the slack in formulating the budget. Chow (1991) and other people thought that budget slack meant budget objective was lower than the deliberate disturbance of the expected level, which may produce negative effects. However, other scholars (Cyert and March, 1963; Merchant, 1989) thought that budget slack may be beneficial to enterprise operation sometimes, because it can become a buffering for enterprises to fight against the uncertainty.

Due to the above contradiction of budget slack, even though there have been lots of researches in the field, the content and results are rather scattered. The rather classical researches explored the factors affecting the budget slack and controlling methods according to the theories of organizational behavior and agency theory, but with various conclusions. Recently, the research has witnessed a further development, and the cause and effect of budget slack has been discussed on the basis of psychology, sociology and strategic management. Meanwhile, the research scope has been expanded to more countries and areas.

For the research on the factors of budget slack, it was more established on the basis of economics, among which the relative representative is agency theory and contingency theory. After encountering with some theory explaining the difficulties, many experimental researches regarded social psychology and organizational behavior as the theoretical basis of the research.

\section{A. Research on the basis of agency theory}

The mode of agency theory proved that the private information possessed by the managers is the significant factors affecting the budget slack (Young, 1985; Merchant, 1985; Dunk, 1993). Weitzman used the method of analysis to put forward a new mode of computing the return on the basis of budget, which could reduce the motivation of the ability of subordinates to conceal or under-report the performance, and guide the subordinate to choose a performance standard or objective equal to the expectation of his future. After the 1980s, 
the mode of Weitzman was integrated with the framework of agency theory, which was called the truth inducing encouragement plan. While traditional one, called the slack inducing encouragement plan, just considered the fix salary and bonus under the situation of finishing the budget.

When enterprises adopt the budget as the main mode of assessing the performance of managers, budget objective becomes the significant decision standard of performance evaluation and managers' salary. So the managers have the motivation to disturb the budget formulation. In the process, managers can use their own private information to affect the budget formulation if all enterprise owners allow managers to have more participation (Chow and other people, 1991; Young, 1985)[8]. Young (1985) designed an experiment that he directly observed the effect of the truth inducing compensation plan on the managers' establishing the budget slack behaviors, but he failed to get related proof to support economic encouragement theories. So he thought that the asymmetry of information is key to the effects on budget behaviors. Later, Waller (1988) proved that when the plan was applied, the participators favoring neutral risks reduced the budget slack but those hating risks didn't. The research of Chow and other people (1988)[7] showed that if there exists information asymmetry, then the slack between these two plans have no difference; otherwise, the slack of the truth inducing compensation plan is obviously reduced. It proved that the compensation plan and information asymmetry mutually affected the performance.

Budget participation is the original factor to connect with budget slack[3]. However, due to different opinions and proofs, there is not a rather unified conclusion about the increasing of the substantial participation of the subordinate will strengthen or restrain the slack budget.

\section{B. Research on the basis of contingency theory}

According to the contingency theory, Stede (2000) summarized the effects of enterprise strategic choices on the budget slack. In his opinion, those enterprises that adopt various or aggressive strategies would be more likely to establish slack budget. Kren and Liao (1988) found that when the uncertainty of external environment is not high, it is hard for the information system of enterprises to distinguish "unintended forecasting bias" and "intentional budgetary slack”. As a result, budget slack becomes inevitable. Besides, the uncertainty of tasks is an important reason for budget slack. And the relationship between them is significant positive correlation (Hirst and Yetton, 1999).

However, according to the research of Pan Fei and Cheng Ming (2007)[1], the information asymmetry and the government intervention were the key factors to explaining the budget slack of the listed companies in our country. But there was no related finding to explain the significant effects of enterprise strategies and growth on budget slack. Furthermore, they concluded that the agency theory could better explain the budget slack behaviors of domestic listed companies than contingency theory. And the research of Zhao Chaomi (2004)[2] showed that the information symmetry and truthoriented compensation plan can prohibit the budget slack to some degree. And the information symmetry has more significant influence. In addition, they found that the accountants from real management departments have lower trend of budget slack, showing the significance of strengthening the professional morality education, especially the staff's, on the budget management.

\section{Research on the basis of introducing organizational behavior and social psychology}

Covaleski and other people (2003), in their review on budget research, discussed the differences from three research perspectives of economics, sociology and psychology, and they thought that the three genres would gradually separate from each other. However, actually, when many recent researchers adopt various theoretical perspectives to make up the shortcomings of purring observing the economics, the introduction of the other two could be eclectic.

1) The planning and controlling of budget have coordinated effects on prohibiting budget slack

Fisher and other people (2002) published an article in American Accounting Review, pointed out that they proved that the resource allocation system and internal information mechanism of the budget have effects on the budget slack. Even though scholars promoted the truth-oriented compensation plan in the recent two or three decades, there are few companies really using it. Obviously, the main reason is that the advantage of traditional compensation plan is better than the cost of budget slack, or the other mechanisms in the budget process hinder the above negative effects.

2) The effects of fame and differentiated investigation on establishing budget slack

Fame can represent one's characteristics or qualities by means of others' opinions and attitudes, and it is based on the performance or behavior more than a period. When the managers have the responsibility of budget, their fame will be affected by how they implement the budget. The previous questionnaire and field researches point out that there were some factors existing in the comparison of budget and reality. Firstly, those managers who usually finish more than the budget (or fail) would have good (bad) performance fame, and they preferred to make the actual performance better than the budget so as to cultivate positive operation fame. Secondly, those who were opposite would have the fame of handing in unreliable budget, which could also restrain the behavior of managers.

The significance of factor difference survey is that if there is no the comparison between the real result and budget and get the reliable judgment, then the upper level will be in trouble assessing the lower level. Firstly, due to various factors including external factors like demand change, estimation error and intentional bias like slack, it is hard for the managers to distinguish these factors in a certain environment, especially the uncertain and various one. Secondly, under the circumstance of highly summarizing the budget report, the managers are hard to find those unreliable budgets without detailed materials, and the lower level can offset the big favored difference of some projects by those great adverse one of other projects. 
Webb (2002)[9] used the experiment to testify the two characteristics of the organization background, namely, the effects of attention to fame and difference survey on the budget slack. From the variance analysis, it is showed that the two factors have significant influences on budget slack and they have mutual functions.

3) The effects of fame and morality recognition on the budget slack

Douglas E. Stevens (2002) adopted the experimental research to testify the effects of fame and morality--two possible controlling factors for the self-interest behavior of the opportunism. The research showed that the lower level still restrained the budget slack to make it lower than the highest in the slack-oriented compensation plan, even after five experimental stages. And the result showed when the related information asymmetry of productive ability increased; the lower level expressed inferior awareness with fame, which reduced the ability of the upper to monitor the budget slack. However, the moral recognition didn't reduce along with the increasing of information asymmetry. All these results showed that, as for these behaviors, fame is a social mechanism on controlling contradicts and coordinating, while morality is an internal coordinating and controlling mechanism.

\section{RESEARCH ON THE ECONOMIC EFFECT OF BUDGET SLACK}

Regarding the budget slack, the western academic field is divided into two kinds of opinions: the harmful and the beneficial.

The first one hold the idea that budget slack will increase the inner cost of enterprises, waste the resources of enterprises, and reduce their operation efficiency. This means that budget slack is opposite to the idea of Kors (1937), namely, the key for enterprises to replacing the market is to save the trade cost. Developing the enterprises operation according to slack budget may make the market trade more efficient than the internal transactions of business management and coordination. So, Haywood (1996) pointed out one of the methods that many enterprises adopt to effectively control the cost is to outsourcing operation. And Esquenazi Shaio (1996) also found that many companies outsource part work of the financial department so as to reduce costs and improve competitiveness. The latter think that the worst is that lots of budget slack will make the staff become dishonest. For example, most enterprises link the realization of budget target with personal performance and compensation according to the traditional budget custom. Then those who prefer the budget slack will be more likely to propose fake budget target and easily get the rewarding. While those honest people will feel harder to manifest their performance even though they pay lots of efforts. Michael Jensen, a Nobel Prize winner, called such disordered phenomenon as paying for the lier (Jensen2001,2003). He thinks that dishonest behaviors or habits will directly destroy the integrity basis of the organization and threaten the longterm development of enterprises.

However, those people who favor "the beneficial" think that it is of great necessity to have budget slack. For instance, Bourageois (1981) pointed out that budget slack could provide a kind of resource guarantee, which is good for relieving the stress of the staff and can help them deal with the risks. Locke and other people (1981) adopted the psychological theories to find that those budget targets hard to finish could have significant positive influence on the performance of enterprises Merchant (1985a) also thought that budget slack could relieve the stress caused by the risk, and give the staff freedom to handle the unexpected situations. Lukka (1988) thought that it is hard to make sure the resources needed in the task before the action, and budget slack could meet the demand. Merchant and Manzoni (1989), using case research,[6] found that 80 to 90 percent of the department managers could reach the budget goals set in advance. They agreed that rather difficult budget targets were satisfying, which could enhance the report quality, resource plan and controlling level of enterprises. In addition, it could motivate managers to relate the budget targets with other factors controlling the system. Fatseas and Hirst (1992) classified the budget targets and compensation contracts, and used the experimental research to find that when the target is middle or higher, it will have positive effects on the performance, regardless of the type of the compensation contract. However, when it comes to a lower target, the type of compensation contract has positive effects on the performance. Oppositely, the type of compensation contract has negative effects on the performance.

\section{CONCLUSION}

This paper concluded the research result of all scholars on budget slack. It can be shown that the research on budget slack in the academic circle began rather late, and there are few experimental studies. Especially domestic researches, due to the design of experimental methods and the difficulties in the implementation process, the present researches are mainly concentrating on the factors affecting the budget behaviors, like the two research results mentioned in the previous paper. Most researches prefer to the theoretical explanation. But due to the lack of solid theoretical support, all opinions vary from each other. They often have various views on the same question, and propose many viewpoints from different angles. As for these problems, the first solution is to promote the circle of academy to further explore related theories and experimental researches; and the other solution is to remind managers to emphasize the attention, utilization and control on budget slack so as to improve the quality of budget management.

\section{REFERENCES}

[1] Pan Fei and Cheng Ming. Influencing factors and economic consequences of budget slack--from the experimental proof of domestic listed companies, Journal of Finance and Economics, 2007 (6):55-66

[2] Zhang Chaomi, Zhuo Yi, Dong Wei and Ge Yan. Experimental study on budget slack behavior, Journal of Management, 2004 (6):46-53

[3] Wan Liangyong. Some thoughts on the problem of budget slack, Modern accountant,2004 (1):25-27

[4] Yu Zengbiao, Zhuo Yi and Hu Chunxiang. A review of contemporary western budget management studies, Foreign Economics \& Management,2003 (12): 18-22

[5] Merchant, K A., Budgeting and the propensity to create budgetary slack, Accounting, Organization and Society, 1985 (10): 201-210 
[6] Merchant, K A.\& J F Manzoni, The achievability of budget targets in profit centers: a field study, The Accounting Review, 1989 (64): 539558

[7] Chow, C W, J Cooper \& W S Waller, Participative budgeting-effects of a truth-inducing pay scheme and information asymmetry on slack and performance, The Accounting Review, 1988 (63):111-122
[8] Young, M S., Participative budgeting: the effects of risk-aversion and asymmetric information on budgetary slack, Journal of Accounting Research, 1985 (23): 829-842

[9] Webb, R A., The impact of reputation and variance investigations on the creation of budget slack, Accounting, Organization and Society, 2002 (27):361-378 